\title{
Determining a Meridian from the Sun
}

\author{
A Readily-Made Pasteboard Instrument \\ By John D. Adams
}

$I^{N}$ $N$ surveying the public lands, the U. S. General Land office makes use of the usual survey-rs' transit equipea with a solar attachment. This evice makes it reardily possible to vetermine a meridian with an accuracy -f a minute or tw in arc -a result, however, that necessitates very close aujustment of the several portions of the mechanism. In its must improved form the attachment is rather formidable in appearance, and in this doubtless lies the reason why so many engineers avoid it and are unfamiliar with its rinciple of operation.

The

the most interesting way - gaining a clear and practical uncerstanding of some seeming obscurity is to provice, where such is possible, a working model reduced to mere essentials, the manimulation of which if it woes not accomplish more than pages of written text will surely aid in eluciating them. It is accoringly the writer's purpese to present, in place of the telescope, mirror, latitule and declination ares of the solar attachment, a simple and interesting device, consisting of tw pieces of cardboar with which an approzimate meriaian may be mechanically determined on precisely the same rinciple that lies nidden in the highly improved instruments used by the United States surveyors. By making such a device in a somewhat more dur-

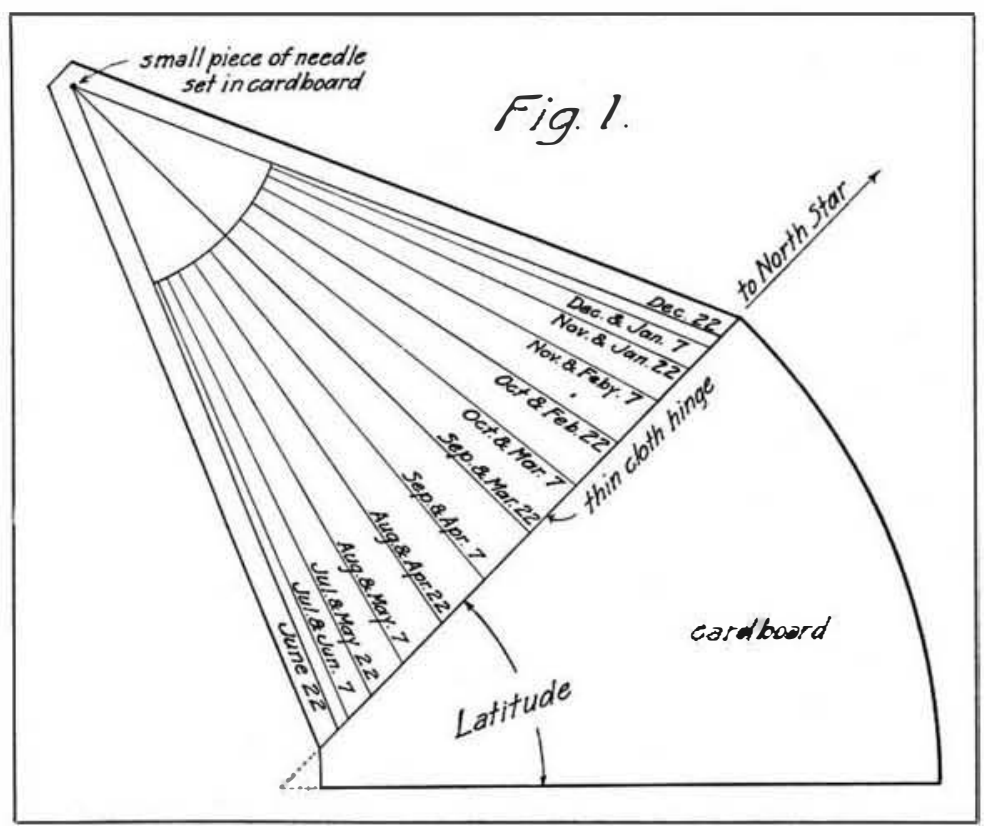

LAY UUT OF THE DEVICE FOR DETERMINING A MERIDIAN FR AM THE SUN

able form, a means will be provided whereby a merid ian may we quicldy wetermined within a degree-a result hardy to we expected with the magnetic needle with all the uncertainties of local attraction.

From the center point on one sice of a piece of smovth, flat carubar erect a perpendicular from four to six inches long. Using a pint near the uper end of this line as a center, draw six raii on the right hand side of the werendicular making the following angles therewith : $23^{\circ}-27^{\prime} ; 22^{\circ}-30^{\prime}$; $19^{\circ}-53^{\prime} ; 15^{\circ}-47^{\prime} ; 10^{\circ}-37^{\prime}$; and $5^{\bullet}-23^{\prime}$. These will ressueshtanthertaim's south declinations, and should be rated as indicated in Fig. 1. On the other sice -f the perpendicular araw six similar raiii for the north aeclinations at the following angles : $23^{\bullet}-27^{\prime} ; 22^{\circ}-41^{\prime} ; 20^{\circ}-20^{1} ; 16^{\bullet}-38^{\prime} ; 12^{\circ}-10^{\prime} ; 6^{\circ}-27^{\prime}$, which are also to be wate as shown.

Cut anther piece of cardourd the exact angle of the latitude of the place where the device is to used, and then fasten the tw pieces together with a thin cloth hinge. Through the central point of the racial lines tightly insert a piece of sewing needle just long enough to project about onesixteenth of an inch on each sice of the cardwoard. At some convenient wint where the sun's rays are available, place the lower edge of the lower piece of carubard on a level surface,

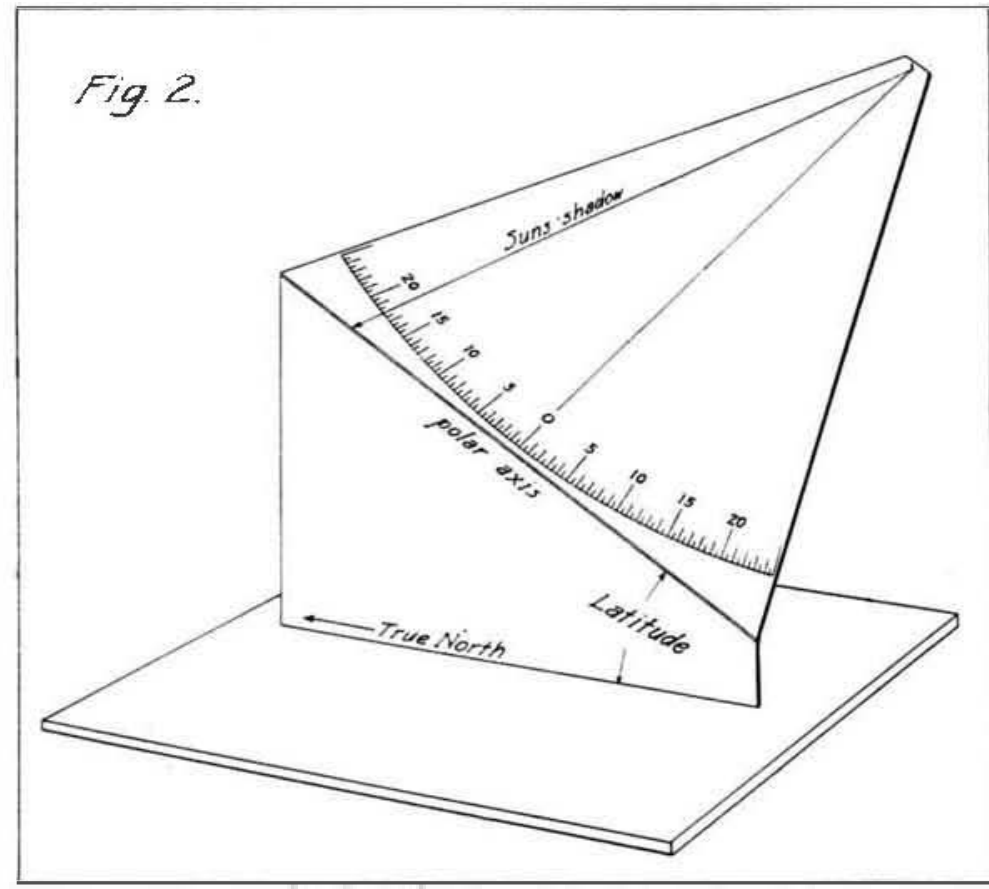

HOW THE PASTEROARD INSTRUMENT IS MOUN TED

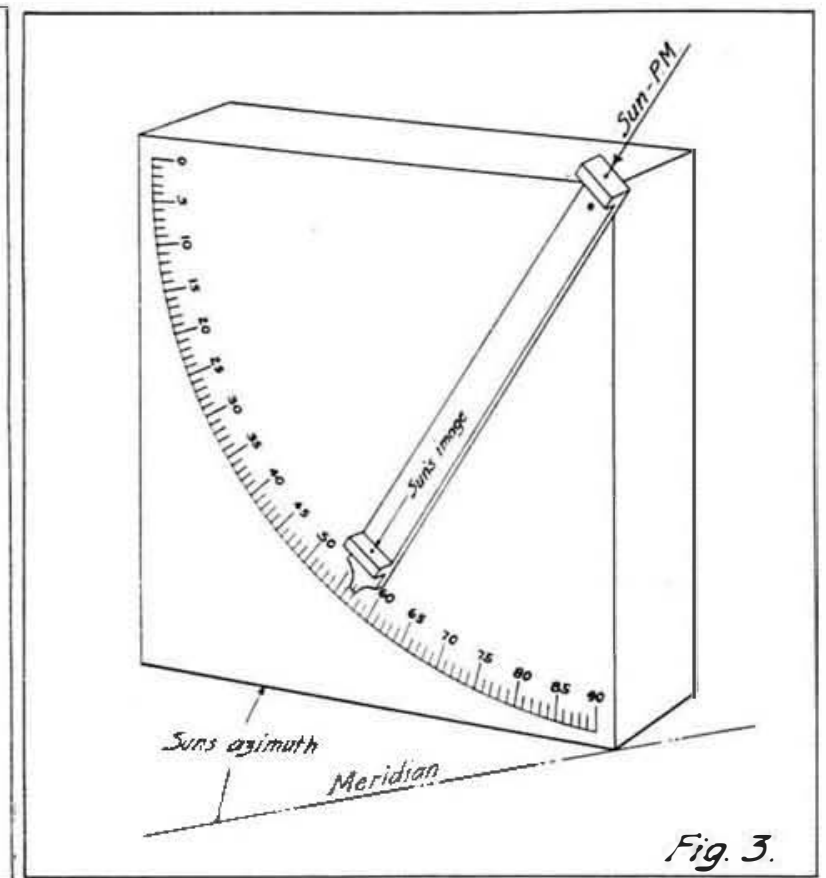

SIMPLE DEVICE FOR 'DIRECT SELAR' AISERVATIONS 
holding the same as nearly vertical as possible with one hand. With the ther manipulate the ther piece of cardbar until the shadow of the piece of needle lengthens out as far as the hinge, when it will be evident that it is in the plane of the sun's rays. While maintaining this condition, move the whole about on the level surface until the shadow falls on the radius corresponding to the date of observation, when it will be found that the vertical iece of carboar is in an exactly north and south pesition. A few trials will shew that in n- ther position will these few simple conditions be met. T• demonstrate this, simply set the latitude section in any posi-

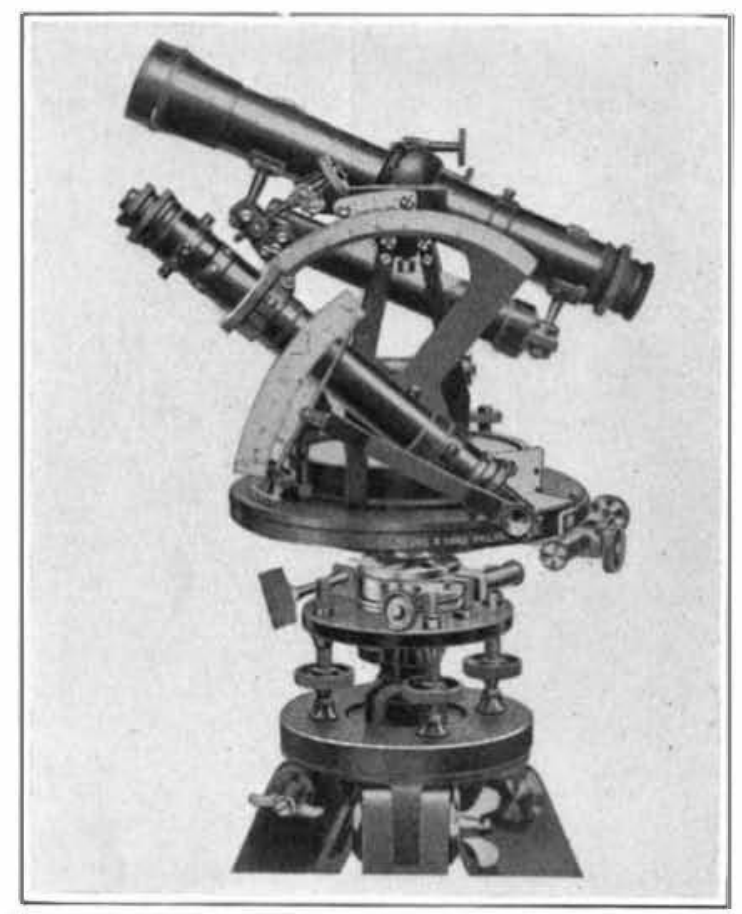

MEUNTAIN ISOLAR TRANISIT, SHEWING ENLARGED LATITUDE AND DECLINATION ARCS

tion ut on the merian, and it will at once be found that at - possible angle of the hinge will the sun's shadow lengthen -ut across the proper date line.

If it is aesire to make the experiment in the afternoun, araw radial limes on the side shown in Fig. 1 ; if in the morning, the ther side should be used, as in Fig. 2. In conunen with the modern solar attachment, the best results cannot be otained within tw or three hours of n॰on, a fact that is not we to any defect in principle, but the smallness of one of the angles in the invelved spherical triangle.

As ur years are not all of the same length the sun's declination is not always the same on identical dates, in consequence - f which more accurate results may be obained by replacing the ate lines with a aeclination arc on either side of the center line. By consulting the current ephemeris of the sun, the exact declination may be determined and then indicated -x the arc by a light pencil mark, through which the sun's shallow may then be cause to pass. By means of a metal protractor having a procting arm, it is a comparatively simple task for a uraftsman to lay ut the necessary scale to at least half iegrees.

It should be understoe that the accuracy of the results apends to a certain extent on having the horizontal surface quite level, a condition, fortunately, that is easy to attain with a piece of boar and a small level. Though not sø impor. tant a condition, the latitule sector should be held vertical, but those wh wish to make use of the device for practical purpeses would, of curse, dispense with the cardbear entirely and construct a base of substantial width that would always stand vertically. The latitule sector culd be male anjustable, the cloth hinge replaced by pivts, and ther improvements would abtless suggest themselves.
It is not the purpese of this article to go int the theory of the solar oservation, as these wh are interested can find it uly expounde in standar works, but it is hoped, after a little experimenting with the carmar molel, that what had previously apeare a very abstruse matter, necessitating a complicated mechanism and elaborate mathematical treatment, is essentially a very simple ilea.

In this connection it may be well to refer to another form - f sølar oservation, als used by the U. S. General Lan effice, called the "direct sølar." The sun is •bserved through the main telescepe of the transit, and its altituce in a ver. tical plane measured. Its azimuth is then calculated by means of the following formula:

\section{Sin Declination}

Cos Azimuth $=$ - Tan Latitude $\times$ Tan Altitude Cos Latitude $\times$ Cos Altitude

For south declinations the sun's declination is considered negative. If the algebraic sign of the result is msitive, the azimuth is referred to the north point; if negative, to the south pint.

In this form of oservation the invelved spherical triangle is solved mathematically, whereas with the solar attachment the solution is effected mecanically. By means of logarithms the above formula is reduced very uickly, and in taking a set of several readings it will be noted that all but the two terms invelving the altitude may be consilered constant.

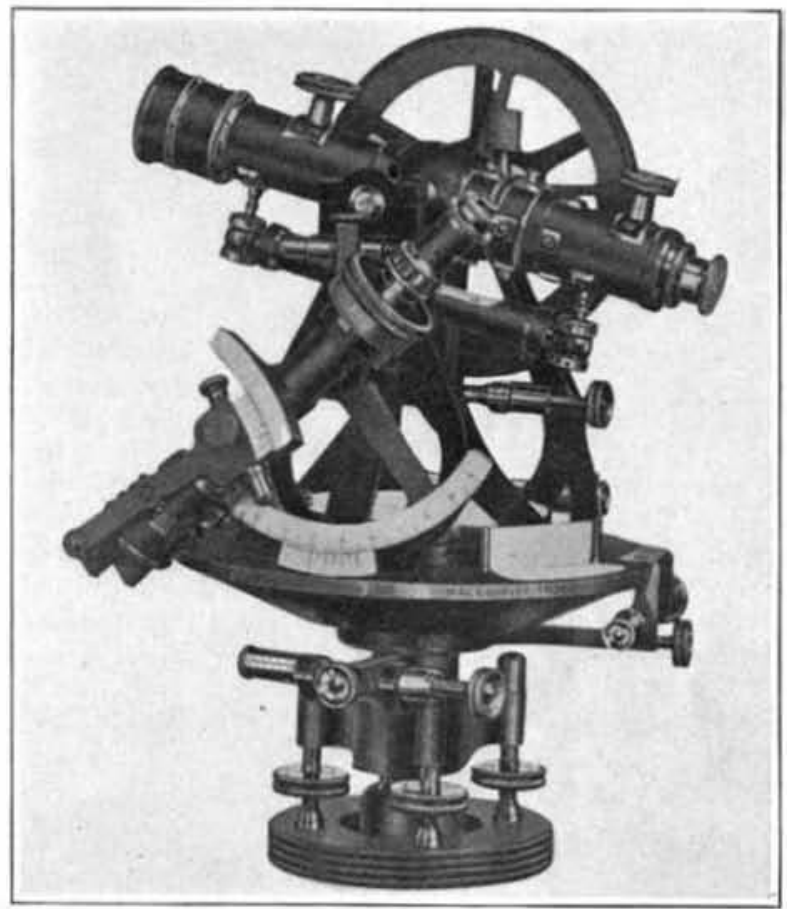

PRECISE TTRANSIT WITIE TELESCOPIC SULAR ATTACFMENT

An interesting and simple means of experimenting with this form of bservation for meridian is illustrated in Fig. 3, and although only paper and woed enter int the construction it is realily possible to determine thereby a north and south line with an error of less than thirty minutes. A well seasoned block about five inches square and an inch and a half thick should be rocurea the mill, where facilities are always available for securing a high iegree of accuracy in sawing. on one surface ony a paper rotractor, realing to thirty minutes, is to be attached by means of glue-the glue being applied toveral small spots rather than the entire surface to prevent warping. In placing the protractor, set the lock on a perfectly flat surface, and line us the $90^{\circ}$ mark with a steel square, which ruay als be used to determine whether the surface of the protratcor stands at right angles with the horizontal sorface. This condition is important, and any slight aljustment that may be necessary may be mace by pasting on a narrow strip of paper along the proper edge 
-f the base. Prepare a small radial arm of the form illustrated, and in the uper projection arill a hole about the size of a pin, so that the sun's rays may pass through and illuminate a small spot on the lower projection. This arm is attached the block by means of a pin or small nail near the upper end put in at the exact center of the protractor. Set the $\operatorname{arm}$ at $90^{\circ}$, and with the steel square resting on the same horizontal surface as the block, make a small not on the lower projection of the arm to indicate where the sun's image should fall.

To determine a meridian, carefully level u any convenient fat surface, on which the block should be moved about until the surface of the protractor is in the plane of the sun. Adjust the angle of the arm until the image falls on the small indicating dot, then recor the sun's direction by awing a line with a shar pencil on the horizental surface using the lower eage of the block as a ruler, after which rea the altitude. The above formula will then give the relation of the sun to the merian, which may laid off with a protractor set on the line prveiously urawn.

Ey consulting an ephemeris it will be seen that for practical purposes the exact time is not a matter of great importance. $T$ avoi the necessity of interpolating with the eye in reading the altitule, one may follow the sun for a minute or tov until the realing is an exact division on the arc, when the mark may then be made on the horizontal surface. This may be remeated several times in a few minutes, and the mean of all the results taken.

A very convenient ephemeris of the sun and Polaris may be had frøm the Superintendent of Documents, Gevernment Printing -ffice, Washingt $\bullet$, for five cents.

AN IMPROVED TOWING SPAR WHICH CAN EE USED AS A NAVIGATIONAL INSTRUMENT.

By Lieur. Commanere S. F. Heim, U. S. Navy.

IN these days of radio compasses and gyro controlled artificial horions, it might be considered rather late to effer a scheme for taking sights bringing the heavenly body down to a spar towed the ship. The writer has real in the U. S. Naval Institute Proceedings of sights being taken on the waterline of an॰ther ship, on a boat sent out by the ship and even on a chi log astern of the shile, but

spar which would seem to be the lagical method because it can be let out frøm the shi with ut støping $\bullet$ altering speed and its istance from the shi can contrelled accurately marks on the tow line.

The scheme seemed so simple and plausible that the writer wondered why it ha not been done before and he in uired of experienced officers and searched the fles of the Naval Institute but failed to find where it ha ever been tried. To test his theory he went out in the bay off Greenbury Point on a sub. marine chaser and steamer both ay and night and to०k sights, using an ordinary towing spar with only 350 feet of line. A small waterprof storage battery light was attached to the spar at night. The results of these trials were accurate far beyond expectations. These resul in altitude difference by Marce Saint-Hilaire method were accurate within 1 minute of arc.

- $f$ course it is realized that conditions here were ideal, with no wave movement of either the spar or the shi ; but it is roposed to eliminate these errors as far as practicable at sea by use of the improved towing spar which will remain afieat with 500 or 600 yards of line out frøm the ship. The longer the length of line the more accurate will be the results. The maximum possible error we to rising and falling of spar in sea will be the angle with tangent equal to maximum rise divided length of tow line. Thus with a 3 -f॰ot rise and fall of spar with 600 yards of line the maximum error would be 5 minutes in altitude.

The three views of the towing spar are self-explanatory an a description is unnecessary. This spar was develoned an used by the commanding officer of the "U. S. S. Charleston" while engaged in convey duty aring the war. The old navy towing spars and special sheet metal tank spars supplied to ships were useless for this work because they would tow under at the distances at which they were desired to be used. The towing under was caused tw things: their shape and the towing line. The improved spar shown in sketch was towed by a small wire rope of about the diameter of a lea encil. This wire line was wound on a small reel secured just forwar of the uarterdeck winch. The spar was haule in by means of the weck winch. It was found that manila line was unsatisfactory for towing

logging and friction tend the spar under. It will be noted that a strong keel or centerbear is attached the spar. This is an important feature which causes it to tow during turns and prevents capsizing.

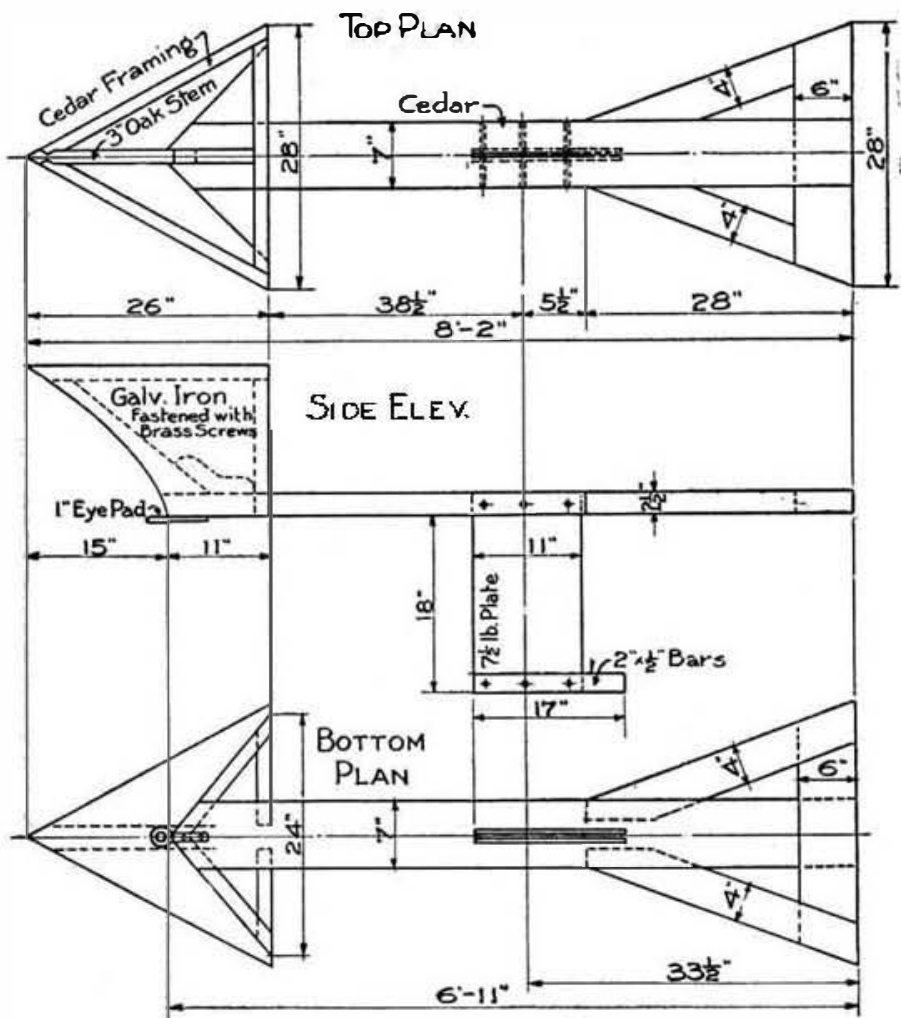

T@WING SPAR USED $\bullet$ THE U. S. S. "CHARLEST

By having at hand a table of "dips" to use for different speeds and lengths of tow line, the operation of taking a sight would be comparatively simple. He could take the bearing of the heavenly body to be observed and then head the shi arectly away from the body and with spar out take a series -f sights. The average of the series should be taken to counteract the errors we to wave heights of the spar. By practice in fair weather when the "dip corrections" are computed he could determine the limits of accuracy and how much confilence to place in it when occasion for its use arrives. We have all experienced the occasion when a sight was highly desirable or even necessary with the sun out or stars shining but $n \bullet$ horizen visible.-Copyrighted by the U. S. Naval Institute. Reprinted by permission, from the Proceedins of the Institute, March, 102

\section{CONCRETE PONTOONS FOR SHIP SALVAGE.}

A SET of reinforced concrete floats have been built by Messrs. Christiani and Nielsen says Le Genie Civil (Feb. 21, $1920)$ for the salvage of ships. The floats are cylindrical and measure 21 meters long and 3.60 meters in diameter. Each float has a bearing capacity of 100 tons and is designed to lift 200 tons. It can withstand an external pressure $2 \mathrm{~kg}$. per $\mathrm{cm}^{2}$ and in exceptional cases $4 \mathrm{~kg}$. per $\mathrm{cm}^{2}$ so that it may be used at depths of 40 meters. 